\title{
CLIWOC: a Cooperative Effort to Recover Climate Data for Oceanic Areas (1750-1850)
}

Ricardo García Herrera1, Dennis Wheeler 2, Gunther Konnen 3, M. Rosario Prieto4, Phil Jones5 On behalf of the CLIWOC project.

1 Universidad Complutense de Madrid, Spain. rgarcía@600aire.fis.ucm.es

2 University of Sunderland, UK. denniswheeler@beeb.net

3 KNMI, The Netherlands. konnen@knmi.nl

4 CRICYT, Mendoza, Argentina. charopri@lanet.com.ar

5 CRU, University of East Anglia, UK. pjones@uea.ac.uk

\section{Logbooks and Climate}

Since at least the time of Christopher Columbus mariners have kept logbook accounts of their voyages. As well as acting as a diary one of the principal functions of a logbook was to assist in safe navigation. This was especially important when ships were out of sight of land and had no easy points of reference with which to determine their position. By 1750 the keeping of logbooks was almost universal amongst the officers on European ships. Although not prepared with this purpose in mind, the logbooks and the detailed observations that they contain are today of great scientific value.

Navigation became a precise science only in the nineteenth century. Before that time more approximate methods had to be used. These all required that wind force and wind direction be carefully recorded, in order to help determine the drift, or 'leeway', made by the ship. Mariners tended also to keep a careful note of other weather phenomena such as rain, thunder, fog and snow even though they had little direct influence on navigation. It is possible to gain an appreciation of the huge volume of climatic data held in the logbooks when it is recalled that observations on the weather were made several times each day whilst the vessel was at sea.

Many logbooks failed to survive the rigorous of life at sea but several thousands have survived intact to the present day. A few date from as long ago as the seventeenth century. Most frequent amongst the survivors are the logbooks of vessels in the state service of imperial nations and in particular those of the naval services. These have now been gathered together in a number of national archives.

The recovery of climate data contained in those logbooks can quanti-

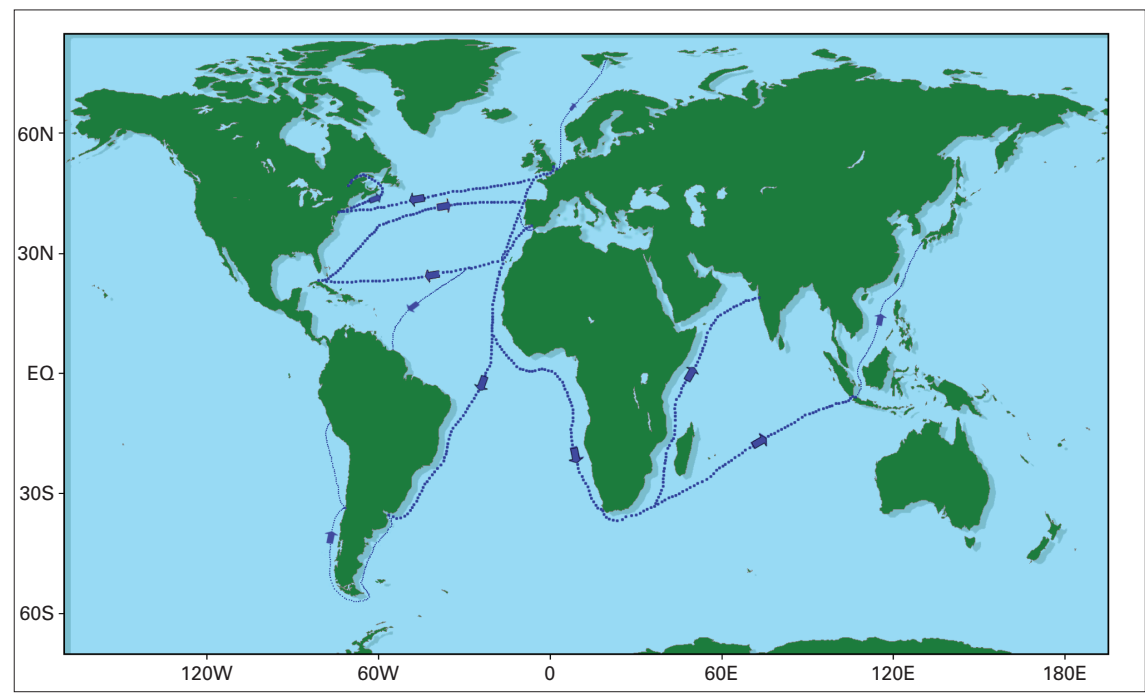

Fig. 1. Most frequented routes during the CLIWOC period.

tatively improve our understanding of climate variability on the decadal to century time scales. This source is of particular interest because it covers a period of time (seventeenth century onwards) and regions (the oceans) for which detailed data are scarce and difficult to obtain by other means. These benefits notwithstanding, the abstraction and collation of these data into a coherent and scientifically useful body of information is both challenging and time-consuming. Currently there are a number of projects aiming to obtain climatic information from observations contained in logbooks from different national navies (eg. Díaz and Woodruf 1999).

\section{The CLIWOC Project}

CLIWOC (Climate Database for the World Oceans) is a project funded by the European Union (January 2001 to December 2003). The principal objective is to realize the scientific potential of logbook climatic data and to produce a database of daily weather observations for the world's oceans between 1750 and 1850. Importantly this database will be freely available to the scientific community. Other objectives are a) to contribute to the understanding of the nature of climatic change over the oceans for the century after 1750 when logbooks become abundant, b) to link with existing data bases that cover the period since the middle of the 19th century, c) through obtaining detailed information from the North Atlantic region to refine our knowledge of the behavior of the NAO for a time before any marked anthropogenic influence on climate can have been made and, d) to stimulate a wider interest in the value of historical documents, but especially logbooks, in climatic research.

The CLIWOC partners are: University Complutense of Madrid (Spain), University of Vigo (Spain), University of Sunderland (UK), KNMI (The Netherlands), University of Leiden (The Netherlands), CRICYT (Argentina) and University of East Anglia (U K). Staff from CDC from NOAA (USA) and the Hadley Centre (UK) act as advisors.

CLIWOC represents one of the most important efforts in digitizing climatic data after the Maury Collection in the USA and the Kobe Collection in Japan (Manabe, 1999). Because of the time period covered by the project, most of the observations 
are in qualitative, descriptive form and, in four different languages. It is the research team's aim to express as much of the data in quantitative form as can be reliably accomplished.

The final CLIWOC database will be linked to that of COADS and will include daily observations from many of the World's major oceanic areas. Figure 1 shows the more frequented sea routes of the period and, consequently, those areas where more information will be available. The data will be presented in a processed form using terms conforming to presentday usage and understanding. Information will be based on the most frequently recorded elements of wind strength and direction but data can also be provided on a wider range of commonly recorded phenomena that include rain and snow, thunder, fog and even the incidence of sea ice cover. To render the database more manageable, annual and decadal summaries will be included. A metadatabase will also allow users to consult the original sources.

While the primary objective of this project is the preparation and dissemination of a daily climatic database for the century 1750 to 1850 , other valuable outcomes will also be achieved. Not least of these is the insight that the logbook information will give to the question of climatic change over oceanic areas. It should be emphasized that no other source provides a basis on which to examine such variation at a daily scale. This unique opportunity will be exploited to its fullest potential while not overlooking the importance of longer term trends in climatic behavior.
CLIWOC partners wish to share their experience with colleagues interested in similar research fields. A workshop is therefore planned for spring 2002 in the Netherlands to host scientists from a variety of fields: climatologists, meteorologists, historians, archivists, geographers and other academics who appreciate the role of historical documents in climatic research.

Further information about CLIWOC can be found at the project web-site: http://www.ucm.es/info/cliwoc/

\section{REFERENCES}

Díaz H and S. D. Woodruff (eds), 1999, Proceedings of the International Workshop on Digitation and Preparation of Historical Marine Data and Metadata (Toledo, Spain, 15-17 September 1997), WMO/ TD-N 957.

Manabe, T. , 1999, 'The Digitized Kobe Collection, Phase I: Historical Surface Marine Meteorological Observations in the Archive of the Japan Meteorological Agency', Bulletin of the American Meteological Society, № 12, 80, 2703-2715.

\section{Paleo-Grassland Research (PGR) 2000: a Conference on the Reconstruction and Modeling of Grass-Dominated Ecosystems}

\author{
Connecticut, USA, 1-3 June 2000
}

Since any single proxy of past vegetation often lacks taxonomic resolution and subsequent ecophysiological information, paleoecological reconstruction and modeling of grassdominated ecosystems is reliant on the information supplied by multiple disciplines and the analysis of multiple proxies. Proficiency in a single proxy demands years of training, thus the success of a multi-proxy approach requires collaboration. The first Paleo-Grassland Research 2000 (PGR2000) workshop in Westbrook, Connecticut fostered such collaboration by bringing together over forty participants, representing twelve countries within North and South America, Europe, Asia and Africa. The primary goals of the meeting were to 1) promote inter-disciplinary collaborative research; 2) to synthesize an informed multi-proxy approach to the reconstruction of past grasslands; 3) establish a network of scientists concerned with grassland paleoecology.

Funding for PGR2000 was provided by the National Science Foundation-Paleoclimate Program and PAGES - Past Global Changes.

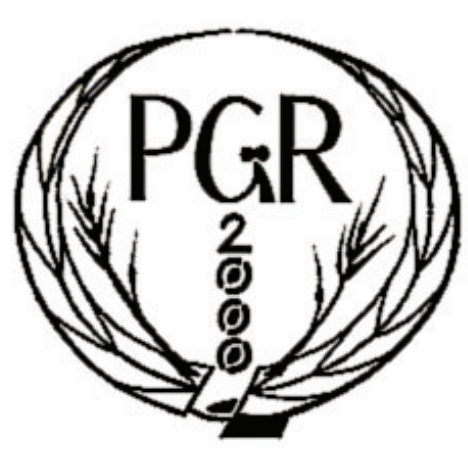

poster session. The size and structure of the workshop allowed delegates to attend all sessions.

\section{Overview Session}

The conference opened with an introductory session with presentations by Matthew Wooller (Carnegie Institution of Washington, USA), Thure Cerling (University of Utah, USA) and Jim Ehleringer (University of Utah, USA) who introduced some fundamental physiological features of the grass family. John Kingtson (Yale University, USA) provided a synthesis of data derived from multiple proxy evidence on the origins of grasslands, while Dan Livingstone (Duke University, USA) introduced grass cuticles, an under-utilized proxy of past grasslands, and discussed issues concerned with their taphonomy.

\section{Pollen and Modeling Session}

The second session was devoted to palynological research and included evidence from South America, including a presentation by Mark Bush (Florida Institute of Technology, USA) on Amazonian pollen sequences 